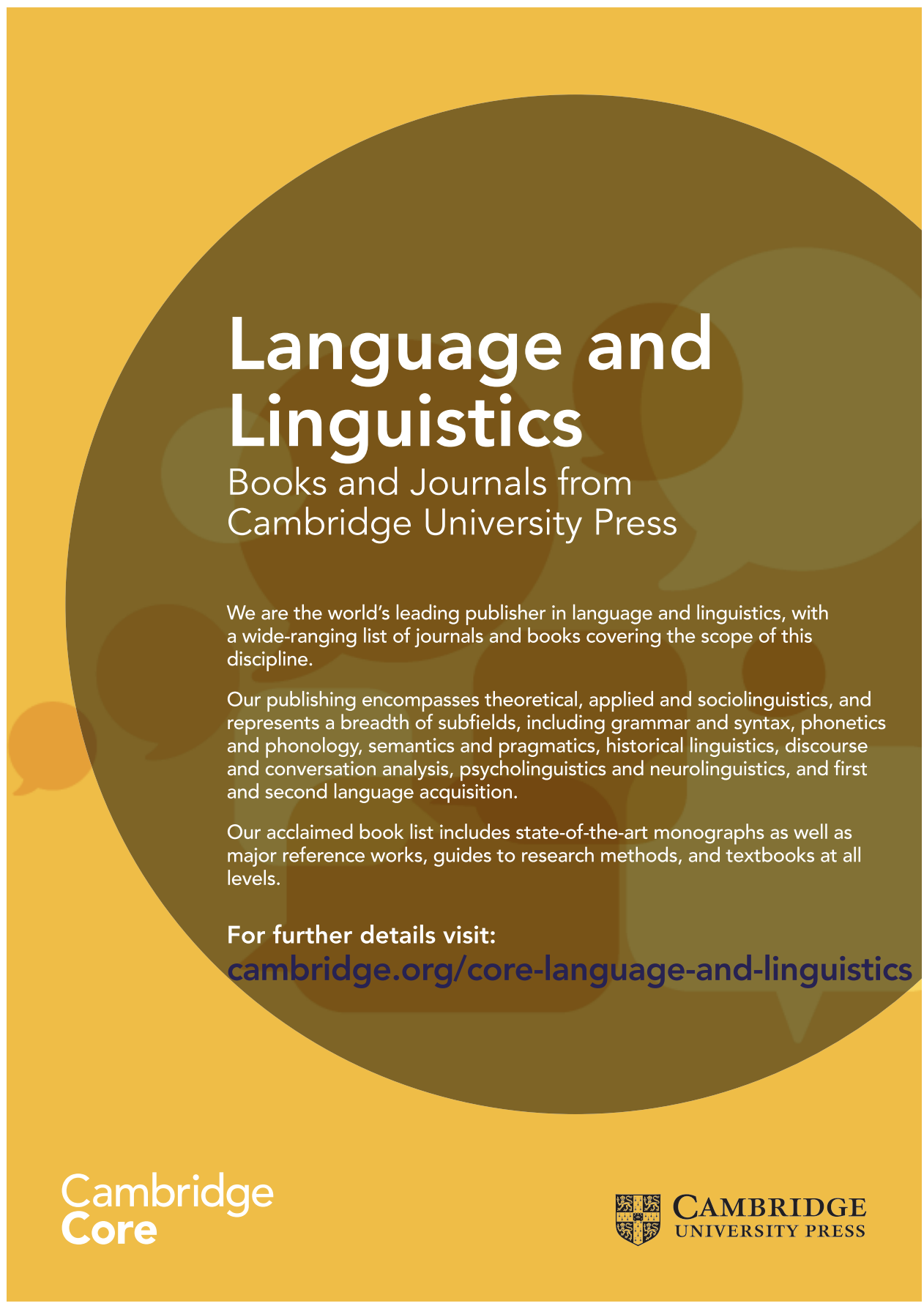


Cambridge Journals Digital Archive

Knowledge is no longer shelved
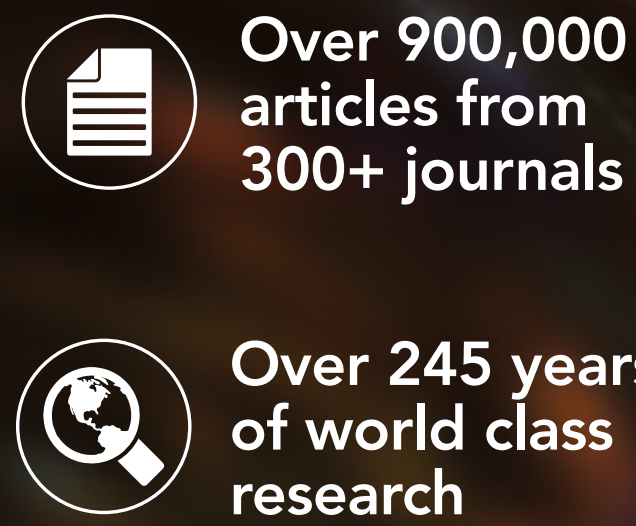

Over 245 years of world class research

Available in collections, bespoke packages and as individual journal archives

cambridge.org/core-cjda 圈園 CAMBRIDGE
UNIVERSITY PRESS 


\title{
Journal of Germanic Linguistics
}

Published for the Society for Germanic Linguistics and the Forum for Germanic Language Studies by Cambridge University Press

\begin{abstract}
Instructions for Contributors
The Journal of Germanic Linguistics (JGL), the journal of the Society for Germanic Linguistics (SGL), carries original articles, reviews, and notes on synchronic and diachronic issues pertaining to Germanic languages and dialects from the earliest phases to the present, including English (to 1500) and the extraterritorial varieties. Contributions are invited on the phonological, morphological, syntactic, and semantic analysis of these languages and dialects, as well as their historical development, both linguistic and textual. Especially welcome are contributions which address questions of interest to a broad range of scholars concerned with general issues in formal theory, sociolinguistics, and psycholinguistics. The JGL places no restrictions on the subject or method of contributions submitted, quality as judged by anonymous peer review being the sole criterion of acceptance, Membership in the SGL is not required for publication; contributions from non-SGL members and from all countries are invited. The language of publication is normally English, though high-quality manuscripts in German will be considered. The JGL is published quarterly, in March, June, September, and December.
\end{abstract}

\section{Editorial Addresses}

Manuscripts for submission should be sent to Prof. Tracy Alan Hall at Indiana University, Department of Germanic Studies, Bloomington, Indiana; email: tahall2@indiana.edu.

Books for review and review manuscripts should be sent to Prof. B. Richard Page, Department of Germanic and Slavic Languages and Literatures, The Pennsylvania State University, 311 Burrowes Building, University Park, PA 16802, USA; e-mail: brp3@psu.edu.

Applications for SGL membership should be sent to Prof. Robert B. Howell, Department of German, University of Wisconsin-Madison, 818 Van Hise Hall, 1220 Linden Drive, Madison, WI 53706, USA; e-mail: rbhowell@facstaff.wisc.edu.

\section{MANUSCRIPTS}

1. Manuscripts of articles must be submitted electronically in PDF format to the Chair of Editorial Committee. Receipt of manuscripts will be promptly acknowledged. They are refereed by at least two competent scholars in a double-blind evaluation process. Authors should not identify themselves in the text. Identification should be provided in a separate file or on a separate sheet giving the title, name of author(s), affiliation, preferred mailing address, and e-mail address. Authors will be informed of a decision within two to four months.

2. When submitting a manuscript, authors should also send by electronic mail an abstract of about 100 words to the Chair of the Editorial Committee. This abstract should also be typed (double spaced) and included with the submitted manuscript.

3. Contributors should make every effort to prepare their manuscripts cleanly and neatly. Manuscripts should be typed double spaced throughout (including abstracts, block quotations, and references) using an 8.5 x 11- inch (or DIN A4) page setting, with no less than 1-inch margins on all four sides.

4. All manuscripts should carefully follow the style sheet of the Linguistic Society of America (as used in Language), except that the JGL uses double quotation marks to introduce quotes that are run into the text. Single quotation marks are used only for glosses and for quotes within quotes. The LSA Style Sheet is printed annually in the December issue of the LSA Bulletin and in abbreviated form on the inside hack cover of Language; it is also available online through the LSA wehsite at www.lsadc.org. Manuscripts not conforming to this style may have to he revised by their authors, especially with regard to references and notes.

5. For accepted manuscripts it will be necessary to submit a final electronic version in a commonly used word-processing program.

6. Submission of an article is taken to imply that it has not been previously published and is not being considered for publication elsewhere. A Copyright Transfer Agreement, with certain specified rights reserved by the author, must be signed and returned to the Chair of the Editorial Committee by senior authors of accepted manuscripts, prior to publication. This is necessary for the wide distribution of research findings, and the protection of both author and the Society under copyright law. 
VOLUME 31.3, 2019

Society for Germanic Linguistics

ARTICLES

Degree resultatives as second-order constructions

$225-297$

Jack Hoeksema and Donna Jo Napoli

Old Norse influence on the language of Beowulf:

$298-322$

A reassessment

Leonard Neidorf and Rafael J. Pascual

\section{Cambridge Core}

For further information about this journal please go to the journal website at: 